\title{
Epidemiological Study of Bell's Palsy in patients From Western
} Nepal.

\author{
Krishna Prasad Koirala ${ }^{1}$ \\ ${ }^{1}$ Department of ENT-HNS,Manipal College of Medical Sciences,Phulbari, Pokhara, Nepal \\ Correspondence: \\ Dr. Krishna Prasad Koirala \\ Associate professor \\ Department of ENT-HNS \\ Manipal College of Medical Sciences \\ Phulbari, Pokhara, Nepal \\ Email: gaukrishna@yahoo.com,gaukrishna9@gmail.com
}

\begin{abstract}
Background: Bell's palsy is defined as idiopathic, sudden onset, unilateral lower motor neuron facial paralysis. The etiology of Bell's palsy is unclear. It affects all age ranges with complete recovery in most cases. However, few patients are left with a considerable permanent functional deficit. The disease has variable progression ranging from few hours to days. Diagnosis is usually made when a patient presents with sudden onset unilateral lower motor neuron facial paralysis without an obvious cause. Different medical therapies such as steroids, antivirals, physiotherapy, acupuncture, etc. have been used to enhance the recovery of Bell's palsy. This study aims to find out the common age of presentation of people with Bell's palsy, and also to report their outcome with the use of steroids. Materials and methods:This study is a prospective observational study carried out in the department of ENT and Head and neck surgery at Manipal College of Medical Sciences, Pokhara, Nepal. Patients of all ages and both sex with the diagnosis of Bell's palsy meeting the inclusion criteria were studied from 1st Jan 2015 to 31st Dec 2018. Data were taken and analyzed with the help of SPSS software and results were published. Results: Out of 45 patients of Bell's palsy enrolled in the study, females outnumbered the males. Bell's palsy was more commonly seen in young adults There was a significant short-term improvement in Bell's palsy with the use of steroids $(p=0.00001)$. There was no difference in early recovery after Bell's palsy regardless of the time of presentation within a week or age of the patient at presentation. Conclusion:Bell's palsy is more common in young adults. Steroids have a definite role in the short-term improvement of facial nerve function. People presenting within a week of facial nerve palsy can be treated with steroids. People of all ages can equally improve with steroid treatment.
\end{abstract}

Key words: Bell's palsy, Short term improvement, Steroids.

$\mathrm{B}$ ell's palsy is defined as idiopathic, sudden onset, unilateral lower motor neuron facial paralysis. ${ }^{1}$ It is a relatively frequent disease all over the world with an overall incidence of 20.2 per 100000 populations. $^{2} \quad$ Etiology of Bell's palsy is unclear and includes anatomical structure, viral infection, ischemia, inflammation, and cold stimulation, etc. ${ }^{3}$ All these factors lead to edema of the facial nerve in the facial canal that leads to stagnation of axoplasmic flow in turn leading to facial paralysis. Because of its extended and convoluted pathway in the temporal bone, the facial nerve is more susceptible to palsy than other cranial nerves in the body.
Bell's palsy affects all age ranges with complete recovery in most cases. However, few patients are left with a considerable permanent functional deficit that leads to psychological, social, and professional problems. ${ }^{4}$ Thus, it is crucial to determine the probable causes of Bell's palsy in time so that targeted treatment approaches can be employed. The disease has variable progression ranging from few hours to days. The secondary cause of facial palsy is to be searched for when the patient presents with slowly progressive facial paralysis. 
Diagnosis is usually made when a patient presents with sudden onset unilateral lower motor neuron facial paralysis without an obvious cause. Other symptoms like pain in and behind the ear, dry mouth, and aural fullness might precede facial paralysis.

Different medical therapies such as steroids, antivirals, physiotherapy, acupuncture, etc. have been used to enhance the recovery of Bell's palsy ${ }^{5-}$ 7. Steroids have been reported to enhance the recovery of disease due to their strong antiinflammatory action. Antiviral drugs have also been prescribed with the suspicion of viral etiology. Eyecare is important as dry eye may lead to corneal ulceration. It includes eye patching and lubrication. Lubricating drops should be applied frequently during the day and eye ointment should be used at night to avoid exposure keratitis. ${ }^{8}$ Although disease recovers spontaneously in many patients, early progression of the disease, grade at presentation, and start of early treatment have been associated with a better outcome in terms of recovery of the disease. ${ }^{9}$

This study is carried out with a hope to find the incidence of Bell's palsy in our scenario, common age at presentation, the time elapsed before treatment, and its outcome with steroid treatment. This will also help the clinicians to choose their treatment protocols, too.

\section{Methods and Materials:}

This is a prospective longitudinal study carried out in the department of ENT and Head and neck surgery at Manipal College of Medical Sciences, Pokhara, Nepal from 1st Jan 2015 to 31 st Dec 2018 (4 years).

Patients of all age and both sex with the diagnosis of Bell's palsy and presenting within 3 days of onset of facial paralysis with no contraindications to steroid treatmentwere enrolled in the study.

Patients with a known cause of Facial palsy e.g. Ramsey- Hunt syndrome, traumatic facial paralysis, other co-morbid illness, contraindication to use of steroids and those not giving consent for the study were excluded.
Objectives: To find out common age of presentation of people with Bell's palsy presenting to our department, to find out the initial grade at a presentation in Bell's palsy and to study the outcome of Bell's palsy with use of steroids.

Patients attending to Manipal Teaching Hospital within 3 days of sudden unilateral lower motor neuron facial paralysis of unknown etiology were admitted to the ENT ward. They were started on intravenous hydrocortisone three times a day for 27 days according to response on treatment. Hydrocortisone was administered $50 \mathrm{mg}$ intravenous three times a day for patients less than $40 \mathrm{~kg}$ weight and $100 \mathrm{mg}$ three times a day for patients more than $50 \mathrm{~kg}$. Degree of facial paralysis was graded according to House-Brackmann facial nerve recovery scale at presentation and discharge (Table 1). ${ }^{10}$ Patients either showing response or no response to medical treatment within a week of hospital stay were discharged on oral prednisolone in a tapering dose for a total of 2 weeks and reviewed in the outpatient department.

Data of age at presentation, side of paralysis, the time-lapse between paralysis and presentation to hospital, grade at presentation, and grade at discharge and after 2 weeks were noted. Data were analyzed with the help of SPSS software and results were published. 
Table 1: House Brackmann grading of facial nerve palsy ${ }^{10}$

\begin{tabular}{|c|c|}
\hline Grade & Characteristics \\
\hline I. Normal & Normal facial function in all areas \\
\hline $\begin{array}{l}\text { II. Mild } \\
\text { dysfunction }\end{array}$ & $\begin{array}{l}\text { Gross } \\
\text { Slight weakness noticeable on close inspection } \\
\text { May have slight synkinesis } \\
\text { At rest, normal symmetry and tone } \\
\text { Motion } \\
\text { Forehead - Moderate to good function } \\
\text { Eye - Complete closure with minimal effort } \\
\text { Mouth - Slight asymmetry }\end{array}$ \\
\hline $\begin{array}{l}\text { III. Moderate } \\
\text { dysfunction }\end{array}$ & $\begin{array}{l}\text { Gross } \\
\text { Obvious but not disfiguring difference between } \\
\text { sides } \\
\text { Noticeable (but not severe) synkinesis, } \\
\text { contracture, or hemifacial spasm } \\
\text { At rest, normal symmetry and tone } \\
\text { Motion } \\
\text { Forehead - Slight to moderate movement } \\
\text { Eye - Complete closure with effort } \\
\text { Mouth - Slightly weak with maximum effort }\end{array}$ \\
\hline $\begin{array}{l}\text { IV. } \\
\text { Moderately } \\
\text { severe } \\
\text { dysfunction }\end{array}$ & $\begin{array}{l}\text { Gross } \\
\text { Obvious weakness and/or disfiguring asymmetry } \\
\text { At rest, normal symmetry and tone } \\
\text { Motion } \\
\text { Forehead - None } \\
\text { Eye - Incomplete closure } \\
\text { Mouth - Asymmetrical with maximum effort }\end{array}$ \\
\hline $\begin{array}{l}\text { V. Severe } \\
\text { dysfunction }\end{array}$ & $\begin{array}{l}\text { Gross } \\
\text { Only barely perceptible motion } \\
\text { At rest, asymmetry } \\
\text { Motion } \\
\text { Forehead - None } \\
\text { Eye - Incomplete closure } \\
\text { Mouth - Slight movement }\end{array}$ \\
\hline $\begin{array}{l}\text { VI. Total } \\
\text { paralysis }\end{array}$ & No movement \\
\hline
\end{tabular}

\section{Results:}

A total of 63 patients were admitted to our hospital with the diagnosis of Bell's palsy from 1st of January 2015 to 31 st December 2018. Out of them, 7 patients had other co-morbid illnesses (diabetes and hypertension) and in 4 patient's steroids were withdrawn from 4th to 7 th day because of increased blood sugar level. Seven patients did not turn up for follow up. Therefore, the final analysis was performed in 45 patients.

There were 19 males and 26 females in our study with a male to female ratio of $1: 1.36$ (Fig.1).

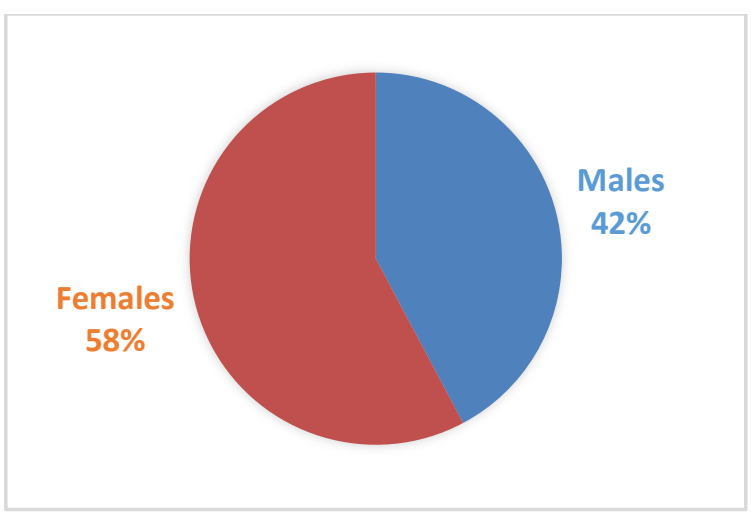

Figure 1. Gender distribution.

The age range was from 6 to 84 years with the mean age of 36.9 years. Bell's palsy was uncommon in children below 10 years of age and adults above 50 years of age. Maximum patients were of the age group 31- 40 years (26.7\%), followed by 21-30 years (17.8\%) (Fig.2).

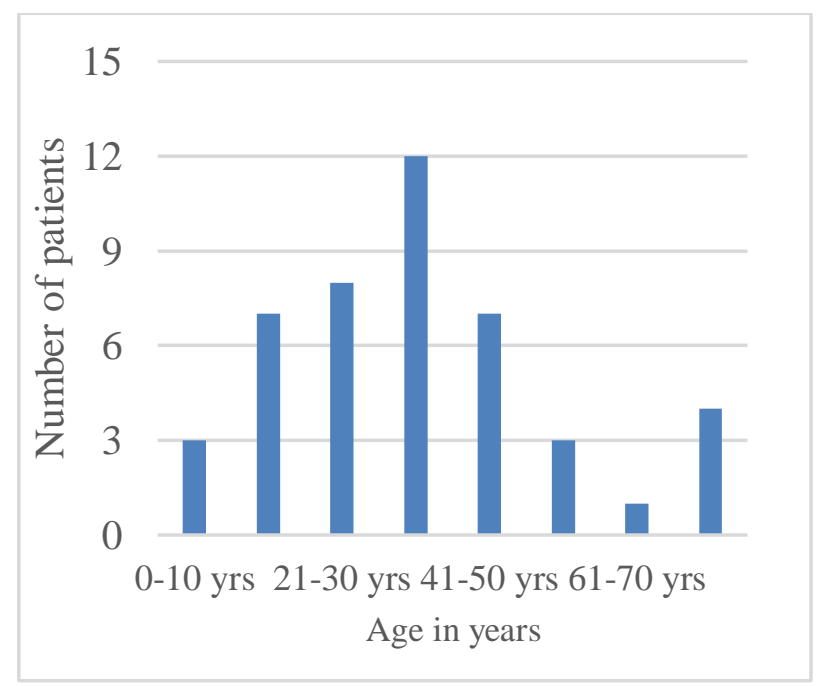

Figure 2. Distribution of patients according to age group.

There was a right-sided predilection. Right side of face was affected in $26(56.8 \%)$ patients and left in $19(42.2 \%)$ patients. The duration from the occurrence of symptoms to presentation to the hospital ranged from 1 day to 10 days with a mean duration of 3.46days. The duration of hospital 
stayranged from 2 to 7 days with an average of 4.57 days.

Out of 45 patients, one patient had grade II facial palsy at the time of presentation, 24 had grade III and 20 had grade IV facial palsy. At the time of discharge, 6 patients had grade I facial palsy, 24 patients had grade II facial palsy, 13 had grade III and 2 had grade IV facial palsy.

There was a significant improvement in facial symptoms in 38 out of $45(84.5 \%)$ patients with the use of steroids. However, 7 patients $(15.5 \%)$ did not improve with the treatment. Symptoms were of the same grade (Grade III) in 6 patients and one patient worsened to Grade III from Grade II instead of treatment. Fisher's exact test applied between Grades I - II and III-IV during a presentation to the hospital and at discharge was significant $(p=$ 0.00001) (Table 2).

Table 2. Grades of facial nerve paresis at presentation and discharge.

\begin{tabular}{lccc}
\hline $\begin{array}{c}\text { Grades of facial nerve } \\
\text { paresis }\end{array}$ & I-II & III-IV & Total \\
\hline Grade at presentation & 1 & 44 & 45 \\
Grade at discharge & 30 & 15 & 45 \\
Total & 31 & 59 & 90 \\
\hline & \multicolumn{3}{c}{ (Fisher's exact test $\mathrm{p}<0.00001$ ) }
\end{tabular}

Twenty-seven patients out of $45(60 \%)$ presented within 3 days of onset of symptoms and 18 patients $(40 \%)$ presented after 3 days of initial symptoms. The outcome was compared between the patients who presented within 3 days to those who presented after 3 days. There was no significant difference in outcome between the two groups (Fisher's exact test, $\mathrm{p}=0.41$ ) (Table 3).
Table 3. Comparison of patients according to days of presentation.

\begin{tabular}{lccc}
\hline Presentation & Improved & Not improved & Total \\
\hline Within 3 days & 24 & 3 & 27 \\
After 3 days & 14 & 4 & 18 \\
Total & 38 & 7 & 45 \\
\hline & & & $(\mathrm{p}=0.41$,Fisher's exact test $)$
\end{tabular}

Similarly, 37 (82.2\%) patients who presented to us were of less than 50 years of age and $8(17.8 \%)$ were more than 50 years of age. The age-related outcome was compared between the age of less than 50 years and more than 50 years. We could not find any significant difference in outcome between the two groups. $((p=0.59$, Fisher exact test) (Table 4)

Table 4: Outcome of patients following the bell's palsy.

\begin{tabular}{lccc}
\hline Age at presentation & Improved & Not improved & Total \\
\hline Up to 50 Years & 32 & 5 & 37 \\
More than 50 Years & 6 & 2 & 8 \\
Total & 38 & 7 & 45 \\
\hline
\end{tabular}

\section{Discussion:}

Lower motor neuron facial nerve palsy is the most common functional disturbance of the cranial nerves. Idiopathic facial palsy (Bell's palsy) constitutes about $60-75 \%$ of all cases of facial paralysis. ${ }^{11}$ Bell's palsy is defined as sudden onset unilateral lower motor neuron facial paralysis of unknown etiology. Clinical practice guidelines have kept the diagnosis of Bell's palsy is one of exclusion, requiring careful clinical elimination of other potential etiologies of facial paralysis such as congenital or syndromic problems, trauma, egneuro, Volume 02, Issue 02, 2020 
infection by agents including zoster and Lyme disease, neoplasms, or postsurgical facial paralysis. ${ }^{12}$ In this study, we tried to study the epidemiology of Bell's palsy and its short term recovery with the use of steroids.

In our study, there were more females than males $(57.8 \%$ vs $42.2 \%)$ with male to female ratio of $1: 1.36$. Our study is consistent with a study performed by Mustafa et al in Sudan where there were $55 \%$ females and $45 \%$ males. ${ }^{13}$ It has been postulated that Bell's palsy is more common in the late weeks of gestation and has a worse outcome. ${ }^{14}$ We had four pregnant ladies with Bell's palsy in our study which accounted for $15.38 \%$ of the total females under study.

In our study, the age of patients suffering from Bell's palsy ranged from 6 to 84 years with the mean age of 36.9 years. Our study is in accordance with studies performed by Priya $R$ et al and Reich $S \mathrm{G}$ et al who have found out the mean age of presentation as 33 and 40 years respectively. ${ }^{15,16}$

We used an optimum dose of steroids to look for the short-term improvement of facial function in Bell's palsy. Hydrocortisone alone in its optimum dose was able to bring significant improvement in symptoms in $84.5 \%$ of patients within a week $(p=0.00001)$. In a meta-analysis, Grogan PM et al concluded that steroids are probably effective in improving facial functional outcomes in Bell's palsy. ${ }^{17}$ In a Randomized, double-blind, placebocontrolled trial, Sulivan FM et al have found that early treatment with prednisolone significantly improves the chances of complete recovery of Bell's palsy at 3 and 9 months. ${ }^{18}$ In a similar study comparing prednisolone and vancyclovir in the outcome of Bell's palsy, it was reported that treatment with prednisolone shortened the time to complete recovery whereas vancyclovir did not affect facial function recovery. ${ }^{19}$ Our study is consistent with their study and shows that there was significant short term improvement with an optimum dose of steroids in patients with Bell's palsy.

The outcome was also compared between patients presenting within 3 days to those presenting from three to seven days. We could not find any significant difference in outcome between the two groups. Our study suggests that there was no difference in early recovery after Bell's palsy regardless of the time of presentation within a week. However, Somasundara D et al have found that patients presenting within 72 hours have a maximum benefit for facial nerve functional outcomes. ${ }^{20}$ Vargish L et al have also suggested for the early use of steroids in Bell's palsy. ${ }^{21}$

Similarly, there was no correlation between age at presentation and recovery of facial function in our study. Fujiwara $\mathrm{T}$ et al reported that age did not correlate with the recovery of facial nerve function. ${ }^{22}$ Similar results have been shown in different studies in the past as well. ${ }^{23,24}$

\section{Conclusion:}

Bell's palsy is more common in young adults of 3140 years of age. Steroids have a definite role in the short-term improvement of facial nerve function. People presenting within a week of facial nerve palsy can be treated with steroids to aim for early recovery. People of all ages can equally improve with the steroid treatment.

\section{References:}

1. Gilden DH. Clinical practice. Bell's palsy. N Engl J Med 2004; 351(13): 1323-31.

2. Rowlands S, Hooper R, Hughes R, Burney P. The epidemiology and treatment of Bell's palsy in the UK. European Journal of Neurology. 2002; 9(1):63 - 7.

3. Zhang W, Xu L, Luo F T, Zhao W B, Li X. The etiology of Bell's palsy: a review. J Neurol 2019. https://doi.org/10.1007/s00415-019-09282-4.

4. Kasse C A, Cruz O L M, Leonhardt F D, Testa J R G, Ferri Ricardo G, Viertler E Y. The value of prognostic clinical data in Bell's palsy. Rev. Bras. Otorrinolaringol. 2005; 71(4): $454-8$.

5. Jeffrey D. T, Khatkhate N. Bell's palsy: Diagnosis and Management. Am Fam Physician. 2007; 76(7):997-1002.

6. Murthy J. M. K., Saxena A B. Bell's palsy: Treatment guidelines. Ann Indian Acad Neurol. 2011 Jul; 14(Supp11): S70-2.

7. Gi N P, Jeong K J, Eun S K, Jung $\mathrm{H} \mathrm{K}$, Young $\mathrm{K}$. Prognostic factors of idiopathic facial palsy: a retrospective study. Acupuncture 2017; 34(3): 23-38.

8. Hughes GB. Practical management of Bell's palsy. Otolaryngol Head Neck Surg. 1990; 102:658-63.

9. Volk GF, Klingner C, Finkensieper M. Prognostication of recovery time after acute peripheral facial palsy: a prospective cohort study BMJ Open 2013; 3: e003007. doi: 10.1136/bmjopen-2013-003007. 
10. House WE. Facial nerve grading system. Otolaryngol Head Neck Surg. 1985; 93:184-93.

11. Heckmann JG, Urban P P, Pitz S, Lichius O G, Gágyor I. The Diagnosis and Treatment of Idiopathic Facial Paresis (Bell's palsy). Dtsch Arztebl Int. 2019 Oct; 116(41): 692702.

12. Baugh RF, Basura GJ, Ishii LE, Schwartz SR, Drumheller CM, Burkholder R et al (2013) Clinical practice guideline: Bell's palsy. Otolaryngol Head Neck Surg 149 (3 Suppl): S1-S27.

13. Mustafa AHK, Sulaiman AM. The Epidemiology and Management of Bell's palsy in Sudan. Open Dent J. 2018; 12:827-36.

14. Phillips KM, Heiser A, Gaudin R, Hadlock TA, Jowett N. Onset of Bell's palsy in late pregnancy and early puerperium is associated with worse long-term outcomes. Laryngoscope. 2017 Dec; 127(12):2854-9.

15. R Priya, S Monga, J Malik, A P Sharma, H Shamim, S Rasool et al. Bell's palsy: Our experience and review of 30 cases. Otorhinolaryngol Head Neck Surg, 2019; (4): 1-3.

16. Bell's palsy. Stephen G. Reich. Continuum (MinneapMinn) 2017; 23(2):447-66.

17. Grogan PM, Gronseth GS. Practice parameter: Steroids, acyclovir, and surgery for Bell's palsy (an evidence-based review): Report of the Quality Standards Subcommittee of the American Academy of Neurology. Neurology. 2001; 56:830-6.

18. Sullivan FM, Swan IR, Donnan PT, Morrison JM, Smith BH, Mc Kinstry B, et al. Early treatment with prednisolone or acyclovir in Bell's palsy. N Engl J Med. 2007; 357:1598-607.

19. Engstrom M, Berg T, Stjernquist-Desatnik A, Axelsson S, Pitkäranta A, Hultcrantz $\mathrm{M}$, et al. Prednisolone and valacyclovir in Bell's palsy: A randomized, double-blind, placebo-controlled, multicentre trial. Lancet Neurol. 2008; 7:993-1000.

20. Somasundara D, Sullivan F. Management of Bell's palsy. Aust Prescr. 2017 Jun; 40(3): 94-7.

21. Vargish L, Schumann SA. For Bell's palsy, start steroids early; no need for an antiviral. J Fam Pract. 2008; 57(1): $22-5$.

22. Fujiwara T, Hato N, Gyo K, Yanagihara N. Prognostic factors of Bell's palsy: prospective patient collected observational study. Eur Arch Otorhinolaryngol. 2014 Jul; 271(7):1891-5.

23. Lee HY, Byun JY, Park MS, Yeo SG. Effect of aging on the prognosis of Bell's palsy. Otol Neurotol. 2013 Jun; 34(4):766-70.

24. Thakur RK, Rajbanshi JN, Khadka S, Nepal PR. Outcome of Bell's Palsy-An Institutional Study. Eastern Green Neurosurgery. 2020 Jan 29;2(1):52-5. 